\title{
Absence of association between pyronaridine in vitro responses and polymorphisms in genes involved in quinoline resistance in Plasmodium falciparum
}

Bruno Pradines ${ }^{*}$, Sébastien Briolant ${ }^{1}$, Maud Henry ${ }^{1}$, Claude Oeuvray ${ }^{2}$, Eric Baret ${ }^{1}$, Rémy Amalvict ${ }^{1}$, Eric Didillon ${ }^{3}$, Christophe Rogier ${ }^{1}$

\begin{abstract}
Background: The aim of the present work was to assess the in vitro cross-resistance of pyronaridine with other quinoline drugs, artesunate and several other commonly used anti-malarials and to evaluate whether decreased susceptibility to pyronaridine could be associated with genetic polymorphisms in genes involved in reduced quinoline susceptibility, such as pfcrt, pfmdr1, pfmrp and pfnhe.

Methods: The in vitro chemosusceptibility profiles of 23 strains of Plasmodium falciparum were analysed by the standard 42 -hour ${ }^{3} \mathrm{H}$-hypoxanthine uptake inhibition method for pyronaridine, artesunate, chloroquine, monodesethylamodiaquine, quinine, mefloquine, lumefantrine, atovaquone, pyrimethamine and doxycycline. Genotypes were assessed for pfcrt, pfmdr1, pfnhe-1 and pfmrp genes.

Results: The $I C_{50}$ values for pyronaridine ranged from 15 to $49 \mathrm{nM}$ (geometric mean $=23.1 \mathrm{nM}$ ). A significant positive correlation was found between responses to pyronaridine and responses to artesunate $\left(r^{2}=0.20 ; P=\right.$ 0.0317 ) but too low to suggest cross-resistance. No significant correlation was found between pyronaridine $I C_{50}$ and responses to other anti-malarials. Significant associations were not found between pyronaridine $I_{50}$ and polymorphisms in pfcrt, pfmdr1, pfmrp or pfnhe-1.

Conclusion: There was an absence of cross-resistance between pyronaridine and quinolines, and the $I_{50}$ values for pyronaridine were found to be unrelated to mutations in the transport protein genes pfcrt, pfmdr1, pfmrp or pfnhe-1, known to be involved in quinoline resistance. These results confirm the interest and the efficacy of the use of a combination of pyronaridine and artesunate in areas in which parasites are resistant to quinolines.
\end{abstract}

\section{Background}

Over the past 20 years, many strains of Plasmodium falciparum have become resistant to chloroquine and other anti-malarial drugs [1]. This development has prompted a search for new effective anti-malarial drugs with minimal side effects. One strategy for reducing the prevalence of malaria is the use of drug combinations, which is thought to protect each drug from the development of resistance

\footnotetext{
* Correspondence: bruno.pradines@free.fr

${ }^{1}$ Unité de Recherche en Biologie et Epidémiologie Parasitaires - Unité de Recherche pour les Maladies Infectieuses et Tropicales Emergentes - UMR 6236, Institut de Recherche Biomédicale des Armées - antenne de Marseille Marseille, France

Full list of author information is available at the end of the article
}

and reduce the overall transmission of malaria [2]. Since 2001, more than 60 countries have officially adopted artemisinin-based combination therapy (ACT) for the treatment of falciparum malaria $[3,4]$. The artemisinin derivatives cause a rapid and effective reduction in parasite biomass as well as gametocyte carriage, while the partner drug, which has a longer duration of action, achieves effective clinical and parasitological cure. Several different forms of ACT have been evaluated, including artesunatesulphadoxine-pyrimethamine [5], artesunate-amodiaquine [6], artemether-lumefantrine [7], artesunate-mefloquine [8], artesunate-chloroproguanil-dapsone [9], artesunate- 
atovaquone-proguanil, dihydroartemisinin-piperaquine [10] and artesunate-pyronaridine [11].

However, clinical failures or at least longer parasite clearance times have been described in Cambodia [12-15]. In addition, prior therapy with an amodiaquinecontaining ACT has been found to select for a reduced response to monodesethylamodiaquine, suggesting that amodiaquine-containing regimens may rapidly lose efficacy in Africa [16]. This emergence of parasite resistance to some forms of ACT indicates that novel compounds and combinations must be discovered and developed.

A pyronaridine-artesunate combination $\left(\right.$ Pyramax $\left.^{\circ}\right)$ is one of the latest ACT combinations currently under development by the not-for-profit organization Medicines for Malaria Venture (Geneva, Switzerland) and the pharmaceutical company Shin Poong Pharmaceuticals (Seoul, Republic of Korea) for the treatment of uncomplicated P. falciparum malaria and for the blood stages of Plasmodium vivax malaria. Pyramax ${ }^{\bullet}$ has recently completed phase III trials in humans.

Pyronaridine, a Mannich base, has been shown to be highly effective against $P$. falciparum and $P$. vivax, with few side effects in clinical trials involving more than 1,000 Chinese patients [17]. Pyronaridine is also effective in children in cases that are resistant to chloroquine [18]. However, there are insufficient preclinical pharmacology data on this combination therapy, and little information exists regarding the mechanisms of action as well as interactions between the two components in terms of anti-malarial activity. Furthermore, there are no reports on the influence of known resistance mechanisms on parasite susceptibility. While antagonism in vitro has been reported for combinations of pyronaridine and dihydroartemisinin or artesunate $[19,20]$, the same combinations demonstrated in vivo synergy in a rodent model [20].

The aims of the present work were as follows: i) to assess the in vitro cross-resistance of pyronaridine with other quinoline drugs, including chloroquine, quinine, mefloquine, monodesethylamodiaquine, lumefantrine, and artesunate, atovaquone, pyrimethamine and doxycycline; and ii) to identify genetic polymorphisms that could be associated with decreased susceptibility to pyronaridine in the genes pfcrt, pfmrp, pfmdr1 and pfnhe-1, which are known to be associated with reduced quinoline susceptibility [21-24], with the goal of identifying molecular markers of pyronaridine resistance for use in resistance surveillance.

\section{Methods}

\section{Plasmodium falciparum cultures}

A total of 23 pre-identified parasite strains (well-characterized laboratory strains or strains obtained from isolates after growth in culture for an extended period of time) from a wide panel of countries (Brazil, Cambodia, Cameroon, Comoros, Djibouti, the Gambia, French Guyana, Honduras, Niger, Republic of Congo, Senegal, Sierra Leone, Sudan, Thailand and Uganda) were maintained in culture in RPMI 1640 (Invitrogen, Paisley, United Kingdom), supplemented with 10\% human serum (Abcys S.A. Paris, France) and buffered with $25 \mathrm{mM}$ HEPES and $25 \mathrm{mM} \mathrm{NaHCO}$. Parasites were grown in type $\mathrm{A}^{+}$human red blood cells under controlled atmospheric conditions that consisted of $10 \%$ $\mathrm{O}_{2}, 5 \% \mathrm{CO}_{2}$ and $85 \% \mathrm{~N}_{2}$ at $37^{\circ} \mathrm{C}$ with a humidity of $95 \%$. All strains were synchronized twice with sorbitol before use [25]. Clonality was verified using PCR genotyping of polymorphic genetic markers $m s p 1, m s p 2$, and microsatellite loci $[26,27]$. The susceptibility of each strain to anti-malarial drugs was assessed in 6 to 21 independent experiments.

\section{Drugs}

Pyronaridine and artesunate were obtained from Shin Poong Pharm Co. (Seoul, Korea). Chloroquine, quinine, pyrimethamine and doxycycline were purchased from Sigma (Saint Louis, MO). Monodesethylamodiaquine was obtained from the World Health Organisation (Geneva, Switzerland). Mefloquine was from Roche (Paris, France), lumefantrine was from Novartis Pharma (Basel, Switzerland) and atovaquone was from GlaxoSmithKline (Evreux, France). Pyronaridine, chloroquine and pyrimethamine were dissolved and diluted in water in concentrations ranging from 0.15 to $100 \mathrm{nM}$ for pyronaridine, 5 to $3200 \mathrm{nM}$ for chloroquine and 5 to 40000 $\mathrm{nM}$ for pyrimethamine. Quinine, monodesethylamodiaquine, mefloquine, artesunate, atovaquone and doxycycline were dissolved first in methanol and then diluted in water to obtain final concentrations ranging from 5 to $3200 \mathrm{nM}$ for quinine, 1.56 to $1000 \mathrm{nM}$ for monodesethylamodiaquine, 3.2 to $400 \mathrm{nM}$ for mefloquine, 0.1 to $100 \mathrm{nM}$ for artesunate, 0.3 to $100 \mathrm{nM}$ for atovaquone and 0.1 to $502 \mu \mathrm{M}$ for doxycycline. Lumefantrine was resuspended and diluted in ethanol to obtain final concentrations ranging from 0.5 to $310 \mathrm{nM}$. Each drug concentration was tested in triplicate in each individual assay.

\section{In vitro assay}

For in vitro isotopic microtests, $200 \mu \mathrm{L} /$ well of a suspension of synchronous parasitized red blood cells (final parasitaemia, $0.5 \%$; final haematocrit, $1.5 \%$ ) was distributed in 96-well plates predosed with anti-malarial drugs. Parasite growth was assessed by adding $1 \mu \mathrm{Ci}$ of tritiated hypoxanthine with a specific activity of $14.1 \mathrm{Ci} / \mathrm{mmol}$ (Perkin-Elmer, Courtaboeuf, France) to each well at time zero. The plates were then incubated for $48 \mathrm{~h}$ in controlled atmospheric conditions. Immediately after 
incubation, plates were frozen and then thawed to lyse erythrocytes. The contents of each well were collected on standard filter microplates (Unifilter GF/B; PerkinElmer) and washed using a cell harvester (Filter-Mate Cell Harvester; Perkin-Elmer). The filter microplates were dried, and $25 \mu \mathrm{L}$ of scintillation cocktail (Microscint O; Perkin-Elmer) was placed in each well. The radioactivity incorporated in nucleotides by the parasites was measured with a scintillation counter (Top Count; Perkin-Elmer).

The drug concentration able to inhibit $50 \%$ of parasite growth $\left(\mathrm{IC}_{50}\right)$ was designated as the concentration at which the tritiated hypoxanthine incorporation reached $50 \%$ of the total incorporation by parasites in the drugfree control wells. The $\mathrm{IC}_{50}$ value was determined by non-linear regression analysis of log-based doseresponse curves (Riasmart, Packard, Meriden, USA).

\section{Nucleic acid extraction}

Total genomic DNA of each strain was isolated using the E.Z.N.A. Blood DNA kit (Omega Bio-Tek, GA, U.S. A.) extraction method. RNA from each strain was purified using the QIAamp Blood Mini kit (QIAGEN, Germany).

\section{pfcrt single nucleotide polymorphisms (SNPs)}

A 1250-nucleotide length fragment of the pfcrt gene was amplified by RT-PCR using F1-sense 5'-TAA TTT CTT ACA TAT AAC AAA ATG AAA TTC-3' and F1-antisense 5'-TTA TTG TGT AAT AAT TGA ATC GAC-3' primers and sequenced using F2-sense 5'-TAG GTG GAG GTT CTT GTC TTG GTA-3' and F2-antisense 5'-TCG ACG TTG GTT AAT TCT CCT TC-3' primers as previously described [28]. Amplifications were performed using the Access RT-PCR System kit (Promega, WI, U.S.A.) according to the manufacturer's instructions. Sequencing was conducted using ABI Prism Big Dye Terminator v1.1 (Applied Biosystems, CA, U.S.A) cycle sequencing ready reaction kits according to the manufacturer's instructions.

\section{pfmdr1 SNPs}

pfmdr1 (PFE1150w) was amplified by PCR using the following primer pairs 5'-AGA GAA AAA AGA TGG TAA CCT CAG-3' and 5'-ACC ACA AAC ATA AAT TAA CGG-3' to amplify codons 86 and 184 and 5'-CAG GAA GCA TTT TAT AAT ATG CAT-3' and 5'-CGT TTA ACA TCT TCC AAT GTT GCA-3' to amplify codons 1034,1042 , and 1246 . The reaction mixture consisted of approximately $200 \mathrm{ng}$ of genomic DNA, $0.5 \mu \mathrm{M}$ of forward and reverse primers, buffer $(50 \mathrm{mM}$ $\mathrm{KCl}, 10 \mathrm{mM}$ Tris, $\mathrm{pH} 8.3$ ), $2.5 \mathrm{mM} \mathrm{MgCl} 2,200 \mu \mathrm{M}$ deoxynucleotide triphosphate (dNTP) and $0.3 \mathrm{U}$ Taq DNA polymerase (Eurogentec) in a final volume of
$50 \mu \mathrm{L}$. The thermal cycler (T3 Biometra) was programmed as follows: an initial $94^{\circ} \mathrm{C}$ for 2 min followed by 40 cycles of $94^{\circ} \mathrm{C}$ for $30 \mathrm{sec}, 52^{\circ} \mathrm{C}$ for $30 \mathrm{sec}$ and $72^{\circ}$ $\mathrm{C}$ for $1 \mathrm{~min}$. A final 15-min extension step was done at $72^{\circ} \mathrm{C}$. The amplified fragments were sequenced as previously described. Sequences were analysed with the software BioEdit Sequence Alignment Editor 7.0.9.0.

\section{pfmrp SNPs}

PCR amplification followed by sequencing was used to detect SNPs in pfmrp at positions 191 and 437. The primers used for amplification and sequencing were pfmrp-501F 5'-TTT CAA AGT ATT CAG TGG GT-3' and $p$ fmrp-1409R 5'-GGC ATA ATA ATT GAT GTA AA-3'.

\section{pfnhe-1 microsatellite profiles}

A sequence containing the previously described ms 4760 microsatellite was amplified using pfnhe-3802F 5'TTATTAAATGAATATAAAGA-3' and pfnhe-4322R 5'-TTTTTTATCATTACTAAAGA-3' primers [29]. The amplified fragments were sequenced as previously described.

\section{Statistical analysis}

Assessment of cross-resistance of standard anti-malarial drugs with pyronaridine was estimated by coefficient of correlation $(r)$ and coefficient of determination $\left(r^{2}\right)$. The Kruskal-Wallis test or Mann-Whitney U test was used, when appropriate, to compare the $\mathrm{IC}_{50}$ values for each gene mutation.. The differences in $\mathrm{IC}_{50}$ for pyronaridine were then tested 19 times (i.e., once per locus). The probability of getting a significant result with 19 tests at the $\alpha$ $=0.05$ level of significance was $1-0.95^{19}$ (1-probability of not getting a significant result with 19 tests). According to the Bonferroni correction, it was concluded that a difference was significant when at least one of the 19 comparisons yielded a significance level below $0.05 / 19=$ 0.0026 .

\section{Results}

Twenty-three P. falciparum strains were tested for their in vitro susceptibility to pyronaridine, artesunate, chloroquine, quinine, mefloquine, monodesethylamodiaquine, lumefantine, atovaquone, pyrimethamine and doxycycline (Additional file 1 and Additional file 2). The mean $\mathrm{IC}_{50}$ values for pyronaridine are shown in Additional file 1. The $\mathrm{IC}_{50}$ values for pyronaridine ranged from 15 to $49 \mathrm{nM}$ (geometric mean $=23.1 \mathrm{nM}, 95 \% \mathrm{CI} 20-26 \mathrm{nM}$ ).

In vitro cross-resistance was measured by pairwise correlation of $\mathrm{IC}_{50}$ values of all 23 strains (Table 1 and Additional file 3). A significant positive correlation was found between responses to pyronaridine and responses to artesunate $\left(r^{2}=0.20 ; P=0.0317\right)$. These coefficients 


\begin{tabular}{|c|c|c|c|c|}
\hline \multicolumn{2}{|r|}{ Drug pair } & \multirow{2}{*}{$\begin{array}{c}\mathbf{r} \\
+0.4488\end{array}$} & \multirow{2}{*}{$\begin{array}{c}\frac{r^{2}}{0.2014} \\
\end{array}$} & \multirow{2}{*}{$\begin{array}{c}\text { P-value } \\
0.0317\end{array}$} \\
\hline PND & AS & & & \\
\hline PND & ATV & +0.3758 & 0.1412 & 0.0772 \\
\hline PND & PY & +0.2116 & 0.0448 & 0.3323 \\
\hline PND & QN & +0.2035 & 0.0414 & 0.3516 \\
\hline PND & MQ & -0.3124 & 0.1050 & 0.1468 \\
\hline PND & DOX & -0.1782 & 0.0318 & 0.4159 \\
\hline PND & LMF & -0.1412 & 0.0199 & 0.5205 \\
\hline PND & MDAQ & -0.1050 & 0.0110 & 0.6335 \\
\hline PND & $\mathrm{CQ}$ & -0.0548 & 0.0030 & 0.8040 \\
\hline
\end{tabular}

of determination were much lower than those for chloroquine and monodesethylamodiaquine $\left(r^{2}=0.84 ; P<\right.$ $0.0001)$, chloroquine and quinine $\left(r^{2}=0.78 ; P<0.0001\right)$ or monodesethylamodiaquine and quinine $\left(r^{2}=0.72\right.$; $P<0.0001)$. No significant correlation was found between pyronaridine $\mathrm{IC}_{50}$ and responses to other antimalarial drugs, with the exception of artesunate.

The following amino acid substitutions were identified for at least one strain: pfcrt M74I, N75E, K76T, A220 S, Q271 (E/V), N326 S, I356T and I371R; pfmrp H191Y and S437A; and pfmdr1 N86Y, Y184F, S1034C, N1042 $\mathrm{D}$ and D1246Y (Additional file 1). Eight different ms4760 microsatellite profiles of $p f n h e-1$ were observed. The number of DNNND and DDNHNDNHNN repeats in ms4760 ranged from 1 to 4 and 1 to 3 , respectively.

No significant association was found between pyronaridine $\mathrm{IC}_{50}(0.0556<P<0.8248)$ and polymorphism in $p f c r t, p f m d r 1, p f m r p$ or $p f n h e-1$. However, significant associations were found between responses to chloroquine, monodesethylamodiaquine, quinine and mefloquine and polymorphism in pfcrt, as well as between responses to monodesethylamodiaquine and quinine and polymorphism in pfmrp (Additional file 4). The associations between ms4760 profiles, number of DNNND repeats and quinine, chloroquine, monodesethylamodiaquine or mefloquine responses were not significant according to the Bonferroni correction $(P<0.05$ but $>$ 0.0026 ). In addition, polymorphism in pfmdr1 (codons 1034 and 1042) and quinine or mefloquine responses were not significantly associated according to the Bonferroni correction $(P<0.05$ but $>0.0026)$.

\section{Discussion}

The continued spread of $P$. falciparum drug resistance to monotherapies has forced a shift toward the use of ACT. Nevertheless, resistance to at least one component of some forms of ACT currently in clinical use has been documented, and it is feared that ACT will gradually lose its clinical efficacy due to widespread use. Individual $P$. falciparum parasites with longer clearance times have been described in Cambodia [12-15]. In addition, prior therapy with an amodiaquine-containing ACT has been found to select for a reduced response to monodesethylamodiaquine, suggesting that amodiaquinecontaining regimens may rapidly lose efficacy in Africa [16]. Antagonistic in vitro drug interactions between pyronaridine and artemisinin derivatives have been described $[19,20,30]$. In addition, previous studies have demonstrated in vitro cross-resistance between pyronaridine and dihydroartemisinin or chloroquine, with coefficients of determination of 0.84 and 0.19-0.46, respectively [31-35]. However, the combination of pyronaridine and artesunate has undergone successful clinical evaluation in Africa [11]. The goal of the present study was to investigate the susceptibility of several strains of $P$. falciparum to pyronaridine, artesunate and the commonly used antimalarial drugs, as well as to determine cross-susceptibilities between these drugs and the molecular determinants of susceptibility.

Twenty-three $P$. falciparum strains were tested for their in vitro susceptibility to pyronaridine, artesunate, chloroquine, quinine, mefloquine, monodesethyamodiaquine, lumefantrine, atovaquone, pyrimethamine and doxycycline. The $\mathrm{IC}_{50}$ values for pyronaridine ranged from 15 to $49 \mathrm{nM}$ (geometric mean $=23.1 \mathrm{nM}, 95 \% \mathrm{CI}$ 20-26 nM). These values are in accordance with previous studies on $P$. falciparum strains (1.9 to $47.8 \mathrm{nM}$ ) [32] or in isolates of Thailand from patients cured with pyronaridine (geometric mean $=15.7 \mathrm{nM}$ ) or that recrudesced after pyronaridine treatment (geometric mean = $23.0 \mathrm{nM}$ ) [33] but higher than those found in isolates from Cameroon (geometric mean $=3.58 \mathrm{nM}$ ), Senegal (geometric mean $=3.8 \mathrm{nM}$ and $4.52 \mathrm{nM}$ ) and Gabon (geometric mean $=3.0 \mathrm{nM}$ and $1.87 \mathrm{nM}$ ) [19,31,34-36]. However, pyronaridine was found to be highly active against chloroquine- and pyrimethamine-resistant strains and against parasites with reduced susceptibility to quinine, monodesethylamodiaquine or mefloquine.

Encouragingly, no correlation was found between pyronaridine and the other quinoline drugs (i.e., chloroquine, quinine, monodesethylamodiaquine, lumefantrine or mefloquine). However, there have been conflicting reports on the correlations between $P$. falciparum responses to pyronaridine and chloroquine. Previous studies showed weak (from 0.13 to 0.26 ) $[31,34,35]$ to middle (0.40 and 0.46$)$ [32,33] coefficients of determination for correlations between pyronaridine and chloroquine. Pyronaridine appeared to be equally effective in vitro against 37 isolates from two areas of Thailand with different chloroquine resistance levels [37]. Similarly, 
Basco and Le Bras showed no correlation between resistance to pyronaridine and chloroquine for 31 isolates from Central and West Africa [38]. These results suggest that no cross-resistance exists between pyronaridine and chloroquine or between pyronaridine and quinoline antimalarial drugs. The potency of pyronaridine against chloroquine-resistant $P$. falciparum strains and those with decreased susceptibility to quinine, monodesethylamodiaquine, or mefloquine, combined with the absence of cross-resistance, suggests that pyronaridine and chloroquine have different modes of action or that different mechanisms of resistance are involved.

In addition, $\mathrm{IC}_{50}$ values for pyronaridine were unrelated to mutations in the transport protein genes $p f c r t$, pfmdr1, pfmrp and pfnhe-1, which are involved in quinoline antimalarial drug resistance. These results are in accordance with the absence of cross-resistance of pyronaridine with quinolines. Qi et al suggested that pyronaridine could be an inhibitor of P-glycoproteinmediated multidrug resistance in tumour cells $[39,40]$. However, this was not confirmed for Pgh1 or PfMRP. Furthermore, because combinations of pyronaridine and mefloquine, quinine, artesunate or dihydroartemisinin have been shown to have antagonistic effects, this hypothesis is of limited interest $[19,30]$. Susceptibilities to these anti-malarial drugs are associated with polymorphisms in ABC transporters, such as Pgh1 and PfMRP [41-45]. However the best association between resistance to mefloquine and a molecular marker is amplification of $p f m d r 1$ gene in southest Asian isolates and not polymorphisms in pfmdr1 [46].

A significant positive correlation was found between responses to pyronaridine and artesunate $\left(r^{2}=0.19\right)$. Nevertheless, this coefficient of determination was lower than those for chloroquine and monodesethylamodiaquine, chloroquine and quinine and monodesethylamodiaquine and quinine. This coefficient of determination was also lower than those obtained in previous studies for dihydroartemisinin (0.31) [19] and artesunate (0.84) [31]. A positive correlation between the $\mathrm{IC}_{50}$ values of two anti-malarial drugs may suggest in vitro cross-resistance or at least common mechanisms of action; however, the relationship between in vitro and in vivo resistance depends on the level of resistance and the coefficients of correlation $(r)$ and determination $\left(r^{2}\right)$. To suggest the same mechanism of action or resistance (which could induce cross-resistance) for two compounds, the coefficient of determination must be high, such as the one for chloroquine and monodesethylamodiaquine $\left(r^{2}=0.84\right)$. A coefficient of determination of 0.19 means that only $19 \%$ of the variation in the response to pyronaridine is explained by variation in the response to artesunate. One explanation for this significant positive correlation is that the range $\mathrm{IC}_{50}$ values for the two drugs is extremely narrow, and most of the strains are still susceptible to the both drugs. The one possible exception is the strain IMT K4 from Cambodia which shows $\mathrm{IC}_{50}$ values higher for pyronaridine (49 $\mathrm{nM})$ and artesunate $(4.0 \mathrm{nM})$. This strain was cultureadapted in 1992 and there was no data on its in vivo response to artemisinin derivatives (or longer clearance time). In addition, in vitro test does not reflect artemisinin derivatives failure or clinical response with longer clearance time: $\mathrm{IC}_{50}$ values are not significantly different between parasites from patients cured and parasites from patient with treatment failure [14].

In this study, the excellent anti-malarial activities of ACT components pyronaridine and artesunate were confirmed, even against parasites resistant to chloroquine or pyrimethamine and with reduced susceptibility to quinine, monodesethylamodiaquine or mefloquine. A five-day regimen of pyronaridine alone (total dose $=$ $1800 \mathrm{mg}$ ) produced a better cure rate than artesunate, artemeter or mefloquine used alone in the same conditions in Thailand [33]. The absence of cross-resistance with quinoline drug and the fact that the $\mathrm{IC}_{50}$ values for pyronaridine were found to be unrelated to mutations in transport protein genes involved in quinoline antimalarial drug resistance confirms the efficacy of the combination of pyronaridine and artesunate for areas in which parasites are resistant to chloroquine or other quinoline drugs [11].

\section{Additional material}

Additional file 1: Table S1: In vitro susceptibility of 23 strains of Plasmodium falciparum to pyronaridine (PND) and pfcrt, pfmdr1, pfmrp and pfnhe-1 polymorphisms.

Additional file 2: Table S2: In vitro susceptibility of 23 strains of Plasmodium falciparum to pyronaridine, chloroquine, quinine, mefloquine, monodesethylamodiaquine, lumefantrine, artesunate, atovaquone, pyrimethamine and doxycycline.

Additional file 3: Table S3: Correlation of in vitro responses of 23 strains of Plasmodium falciparum to pyronaridine (PND), chloroquine (CQ), quinine (QN), mefloquine (MQ), monodesethylamodiaquine (MDAQ), lumefantrine (LMF), artesunate (AS), atovaquone (ATV), pyrimethamine (PY) and doxycycline (DOX). Additional file 4: Table S4: Association between in vitro responses $\left(\mathrm{IC}_{50}\right)$ to pyronaridine (PND), artesunate (AS), chloroquine (CQ), monodesethylamodiaquine (MDAQ), quinine (QN), mefloquine (MQ) and polymorphisms in the pfnhe-1, pfort, pfmdr1 and pfmrp genes of 23 strains of Plasmodium falciparum.

\section{Acknowledgements}

This work was supported by the Direction Centrale du Service de Santé des Armées and Medicines for Malaria Venture.

\section{Author details}

${ }^{1}$ Unité de Recherche en Biologie et Epidémiologie Parasitaires - Unité de Recherche pour les Maladies Infectieuses et Tropicales Emergentes - UMR 6236, Institut de Recherche Biomédicale des Armées - antenne de Marseille, 
Marseille, France. ${ }^{2}$ Medicines for Malaria Venture, Geneva, Switzerland. ${ }^{3}$ Fulcrum Pharma (Europe) Ltd, Hemel Hempstead, UK.

\section{Authors' contributions}

CO, ED and BP conceived and designed the experiments. EB and RA performed the in vitro experiments. $\mathrm{MH}$ and $\mathrm{SB}$ performed the genotyping. CR and BP analysed the data. CO, ED, CR and BP wrote the paper. All authors read and approved the final manuscript.

\section{Competing interests}

The authors declare that they have no competing interests.

Received: 9 August 2010 Accepted: 25 November 2010

Published: 25 November 2010

\section{References}

1. Le Bras J, Musset L, Clain J: Antimalarial drug resistance. Med Maladies Infect 2006, 36:401-405

2. White NJ: Preventing antimalarial drug resistance through combinations. Drug Resist Updat 2001, 1:3-9.

3. Nosten F, White NJ: Artemisinin-based combination treatment of falciparum malaria. Am J Trop Med Hyg 2007, 77:181-192.

4. Eastman RT, Fidock DA: Artemisinin-based combination therapies: a vital tool in efforts to eliminate malaria. Nat Rev Microbiol 2009, 7:864-874.

5. Von Seidlein L, Milligan P, Pinder M, Bojang K, Anyalebechi C, Gosling R, Coleman R, Ude Jl, Sadiq A, Duraisingh M, Warhurst D, Alloueche A, Target G, Mcadam K, Greenwood B, Walraven G, Olliaro P, Doherty T: Efficacy of artesunate plus pyrimethamine-sulphadoxine for uncomplicated malaria in the Gambian children: a double-blind, randomized, controlled trial. Lancet 2000, 355:352-357.

6. Brasseur P, Agnamey P, Gaye O, Vaillant M, Taylor WRJ, Olliaro PL: Efficacy and safety of artesunate plus amodiaquine in routine use for the treatment of uncomplicated malaria in Casamance, southern Senegal. Malar J 2007, 6:150.

7. Yeka A, Dorsey G, Kamya RM, Talisuna A, Lugemwa M, Rwakimari JB, Staedke SG, Rosenthal PJ, Wabwire-Mangen F, Bukirwa H: Artemetherlumefantrine versus dihydroartemisinin-piperaquine for treating uncomplicated malaria: a randomized trial to guide policy in Uganda. Plos One 2008, 3:2390.

8. Ashley EA, Lwin KM, Mcgready R, Simon WH, Phaiphun L, Proux S, Wangseang N, Taylor W, Stepniewska K, Nawamaneerat W, Thwai KL, Barends M, Leowattana W, Olliaro P, Singhasivanon P, White NJ, Nosten F: An open label randomized comparison of mefloquine-artesunate as separate tablets vs. a new co-formulated combination for the treatment of uncomplicated multidrug-resistant falciparum malaria in Thailand. Trop Med Int Health 2006, 11:1653-1660.

9. Premji Z, Umeh RE, Owusu-Agyei S, Esamai F, Ezedinachi EU, Oguche S, Borrmann S, Sowunmi A, Duparc S, Kirby PL, Pamba A, Kellam L, Guiguemdé R, Greenwood B, Ward SA, Winstanley PA: ChlorproguanilDapsone_Artesunate versus Artemether-Lumefantrine: A randomized, double-blind phase III trial in African children and adolescents with uncomplicated Plasmodium falciparum malaria. PlosOne 2009, 4:6682.

10. Bassat $Q$, Mulenga $M$, Tinto $H$, Piola $P$, Borrmann $S$, Menendez $C$, Nambozi M, Valea I, Nabasumba C, Sasi P, Bacchieri A, Corsi M, Ubben D, Talisuna A, D'Alessandro U: Dihydroartemisinin-piperaquine and artemether-lumefantrine for treating uncomplicated malaria in African children: a randomized, non-inferiority trial. PlosOne 2009, 4:7871.

11. Ramharter M, Kurth F, Schreier AC, Nemeth J, Glasenapp I, Bélard S, Schlie M, Kammer J, Koumba PK, Cisse B, Mordmüller B, Lell B, Issifou S, Oeuvray C, Fleckenstein L, Kremsner PG: Fixed-dose pyronaridineartesunate combination for treatment of uncomplicated falciparum malaria in pediatric patients in Gabon. J Infect Dis 2008, 198:911-919.

12. Noedl H, Se Y, Schaecher K, Smith BL, Socheat D, Fukuda MM: Evidence of artemisinin-resistant malaria in western Cambodia. N Engl J Med 2008, 359:2619-2620

13. Carrara VI, Zwang J, Ashley EA, Price RN, Stepniewska K, Barends M, Brockman A, Anderson T, McGready R, Phaiphun L, Proux S, van Vugt M, Hutagalung $R$, Lwin KM, Phyo AP, Preechapornkul $P$, Imwong $M$, Pukrittayakamee S, Singhasivanon P, White NJ, Nosten K: Changes in the treatment responses to artesunate-mefloquine on the Northwestern border of Thailand during 13 years of continuous deployment. PlosOne 2009, 4:4451.

14. Dondorp AM, Nosten F, Yi P, Das D, Phyo AP, Tarning J, Lwin KM, Ariey F, Hanpithakpong W, Lee SJ, Ringwald P, Silamut K, Imwrong M, Chotivanish K, Lim P, Herdman T, An SS, Yeung S, Singhasivanon P, Day NPJ, Lindegardh N, Socheat D, White NJ: Artemisinin resistance in Plasmodium falciparum malaria. N Engl J Med 2009, 361:455-467.

15. Rogers WO, Sem R, Tero T, Chim P, Lim P, Muth S, Socheat D, Ariey F, Wongsrichanalai $C$ : Failure of artesunate-mefloquine combination therapy for uncomplicated Plasmodium falciparum malaria in southern Cambodia. Malar J 2009, 8:10.

16. Nawaz F, Nsobya SL, Kiggundu M, Joloba M, Rosenthal PJ: Selection of parasites with diminished drug susceptibility by amodiaquine-containing antimalarial regimens in Uganda. J Infect Dis 2009, 200:1650-1657.

17. Shao BR: A review of antimalarial drug pyronaridine. Chin Med J 1990, 103:428-434.

18. Ringwald P, Bickii J, Basco LK: Efficacy of oral pyronaridine for the treatment of acute uncomplicated falciparum malaria in African children. Clin Infect Dis 1998, 26:946-953.

19. Ringwald $P$, Moukoko Eboumbou CE, Bickii J, Basco LK: In vitro activities of pyronaridine, alone and in combination with other antimalarial drugs, against Plasmodium falciparum. Antimicrob Agents Chemother 1999, 43:1525-1527.

20. Vivas L, Rattray L, Stewart L, Bongard E, Robinson BL, Peters W, Croft SL: Anti-malarial efficacy of pyronaridine and artesunate in combination in vitro and in vivo. Acta Trop 2008, 105:222-228.

21. Fidock DA, Nomura T, Talley AK, Cooper RA, Dzekunov SM, Ferdig MT Ursos LMB, Sidhu ABS, Naudé B, Deitsch KW, Su XZ, Wootton JC, Roepe PD, Wellems TE: Mutations in the $P$. falciparum digestive vacuole transmembrane protein PfCRT and evidence for their role in chloroquine resistance. Mol Cell 2000, 6:861-871.

22. Henry M, Alibert S, Orlandi-Pradines E, Bogreau H, Fusai T, Rogier C, Barbe J, Pradines B: Chloroquine resistance reversal agents as promising antimalarial drugs. Curr Drug Targets 2006, 7:935-948.

23. Henry M, Alibert S, Rogier C, Barbe J, Pradines B: Inhibition of efflux of quinolines as new therapeutic strategy in malaria. Curr Top Med Chem 2008, 8:563-578.

24. Henry M, Briolant S, Zettor A, Pelleau S, Baragatti M, Baret E, Mosnier J, Amalvict R, Fusai T, Rogier C, Pradines B: Plasmodium falciparum $\mathrm{Na}^{+} / \mathrm{H}^{+}$ exchanger 1 transporter is involved in reduced susceptibility to quinine. Antimicrob Agents Chemother 2009, 53:1926-1930.

25. Lambros C, Vanderberg JP: Synchronization of Plasmodium falciparum erythrocytic stages in culture. J Parasitol 1979, 65:418-420.

26. Bogreau H, Renaud F, Bouchiba H, Durand P, Assi SB, Henry MC, Garnotel E, Pradines B, Fusai T, Wade B, Adehossi E, Parola P, Kamil MA, Puijalon O, Rogier C: Genetic diversity and structure of African Plasmodium falciparum populations in urban and rural areas. Am J Trop Med Hyg 2006, 74:953-959.

27. Henry M, Diallo I, Bordes J, Ka S, Pradines B, Diatta B, M'Baye PS, Sane M, Thiam M, Gueye PM, Wade B, Touze JE, Debonne JM, Rogier C, Fusai T: Urban malaria in Dakar, Senegal: chemosusceptibility and genetic diversity of Plasmodium falciparum isolates. Am J Trop Med Hyg 2006, 75:146-151.

28. Durrand V, Berry A, Sem R, Glaziou P, Beaudou J, Fandeur T: Variations in the sequence and expression of the Plasmodium falciparum chloroquine resistance transporter (Pfcrt) and their relationship to chloroquine resistance in vitro. Mol Biochem Parasitol 2004, 136:273-285.

29. Ferdig MT, Cooper RA, Mu J, Deng B, Joy DA, Su XZ, Wellems TE: Dissecting the loci of low-level quinine resistance in malaria parasites. Mol Microbiol 2004, 52:985-997.

30. Davis TM, Hamzah J, llett KF, Karunajeewa HA, Reeder JC, Batty KT, Hackett S, Barrett PHR: In vitro interactions between piperaquine, dihydroartemisinin, and other conventional and novel antimalarial drugs. Antimicrob Agents Chemother 2006, 50:2883-2885.

31. Kurth F, Pongratz $P$, Bélard $S$, Mordmüller B, Kremsner PG, Ramharter M: In vitro activity of pyronaridine against Plasmodium falciparum and comparative evaluation of anti-malarial drug susceptibility assays. Malar J 2009, 8:79.

32. Elueze El, Croft SL, Warhurst DC: Activity of pyronaridine and mepacrine against twelve strains of Plasmodium falciparum in vitro. J Antimicrob Chemother 1996, 37:511-518. 
33. Looareesuwan $S$, Kyle DE, Vivaran C, Vanijanonta S, Wilairatana $P$, Wernsdorfer WH: Clinical study of pyronaridine for the treatment of acute uncomplicated falciparum malaria in Thailand. Am J Trop Med Hyg 1996, 54:205-209.

34. Pradines B, Tall A, Parzy D, Spiegel A, Fusai T, Hienne R, Trape JF, Doury JC: In vitro activity of pyronaridine and amodiaquine against African isolates (Senegal) of Plasmodium falciparum in comparison with standard antimalarial agents. J Antimicrob Chemother 1998, 42:333-339.

35. Pradines B, Mabika Mamfoumbi M, Parzy D, Owono Medang M, Lebeau C, Mourou Mbina JR, Doury JC, Kombila M: In vitro susceptibility of African isolates of Plasmodium falciparum from Gabon to pyronaridine. Am J Trop Med Hyg 1999, 60:105-108.

36. Pradines B, Tall A, Ramiandrasoa F, Spiegel A, Sokhna C, Fusai T, Mosnier J, Daries W, Trape JF, Kunesch G, Parzy D, Rogier C: In vitro activity of ironbinding compounds against Senegalese isolates of Plasmodium falciparum. J Antimicrob Chemother 2006, 57:1093-1099.

37. Childs GE, Hausler B, Milhous W, Chen C, Wimonwattrawatee T, Pooyindee N, Boudreau EF: In vitro activity of pyronaridine against field isolates and reference clones of Plasmodium falciparum. Am J Trop Med Hyg 1988, 38:24-29.

38. Basco LK, Le Bras J: In vitro activity of pyronaridine against African strains of Plasmodium falciparum. Ann Trop Med Parasitol 1992, 86:447-454.

39. Qi J, Yang CZ, Wang CY, Wang SB, Yang M, Wang JH: Function and mechanism of pyronaridine: a new inhibitor of P-glycoprotein-mediated multidrug resistance. Acta Pharmacol Sin 2002, 23:544-550.

40. Qi J, Wang S, Liu G, Wang J, Zhu Z, Yang C: Pyronaridine, a novel modulator of P-glycoprotein-mediated multidrug resistance in tumor cells in vitro and in vivo. Biochem Biophys Res Commun 2004, 319:1124-1131.

41. Reed MB, Saliba K, Caruana SR, Kirk K, Cowman AF: Pgh1 modulates sensitivity and resistance to multiple antimalarials in Plasmodium falciparum. Nature 2000, 403:906-909.

42. Sidhu AB, Valderramos SG, Fidock DA: Pfmdr1 mutations contributed to quinine resistance and enhance mefloquine and artemisinin sensitivity in Plasmodium falciparum. Mol Microbiol 2005, 57:913-926.

43. Sidhu AB, Uhlemann AC, Vaderramos SG, Valderramos JC, Krishna S, Fidock DA: Decreasing pfmdr1 copy number in Plasmodium falciparum malaria heightens susceptibility to mefloquine, lumefantrine, halofantrine, quinine, and artemisinin. J Infect Dis 2006, 194:528-535.

44. Ursing J, Zakeri S, Gil JP, Bjorkman A: Quinoline resistance associated polymorphisms in the pfcrt, pfmdr1 and pfmrp genes of Plasmodium falciparum in Iran. Acta Trop 2006, 97:352-356.

45. Pradines B, Parquet V, Orlandi-Pradines E: ABC Transporters in Plasmodium falciparum and their involvement in resistance to animalarial drugs. In $A B C$ transporters in microorganisms. Edited by: Ponte-Sucre A. UK: Horizon Scientific Press; 2009:113-127.

46. Price RN, Uhlemann AC, Brockman A, McGready R, Ashley E, Phaipun L, Patel R, Laing K, Looareesuwan S, White NJ, Nosten F, Krishna S: Mefloquine resistance in Plasmodium falciparum and increased pfmdr1 gene copy number. Lancet 2004, 364:438-447.

doi:10.1186/1475-2875-9-339

Cite this article as: Pradines et al:: Absence of association between pyronaridine in vitro responses and polymorphisms in genes involved in quinoline resistance in Plasmodium falciparum. Malaria Journal 2010 9:339.

\section{Submit your next manuscript to BioMed Central and take full advantage of:}

- Convenient online submission

- Thorough peer review

- No space constraints or color figure charges

- Immediate publication on acceptance

- Inclusion in PubMed, CAS, Scopus and Google Scholar

- Research which is freely available for redistribution

Submit your manuscript at www.biomedcentral.com/submit
Biomed Central 